\title{
A retrospective population based trend analysis on hospital admissions for lower respiratory illness among Swedish children from 1987 to 2000 \\ Ove Björ*†1 and Lennart Bråbäck ${ }^{\dagger 2}$
}

Address: ${ }^{1}$ Mid-Sweden Epidemiological Centre, Västernorrland County Council, Sundsvall Hospital, SE-851 86 Sundsvall, Sweden and ${ }^{2}$ MidSweden Research and Development Centre, Västernorrland County Council, Sundsvall Hospital, SE-851 86 Sundsvall, Sweden

Email: Ove Björ* - ove.bjor@lvn.se; Lennart Bråbäck - lennart.braback@lvn.se

* Corresponding author †Equal contributors

Published: II July 2003

BMC Public Health 2003, 3:22
Received: 27 March 2003

Accepted: II July 2003

This article is available from: http://www.biomedcentral.com/I47/ -2458/3/22

(C) 2003 Björ and Bråbäck; licensee BioMed Central Ltd. This is an Open Access article: verbatim copying and redistribution of this article are permitted in all media for any purpose, provided this notice is preserved along with the article's original URL.

\begin{abstract}
Background: Data relating to hospital admissions of very young children for wheezing illness have been conflicting. Our primary aim was to assess whether a previous increase in hospital admissions for lower respiratory illness had continued in young Swedish children. We have included readmissions in our analyses in order to evaluate the burden of lower respiratory illness in very young children. We have also assessed whether changes in the labelling of symptoms have affected the time trend.
\end{abstract}

Methods: A retrospective, population based study was conducted to assess the time trend in admissions and re-admissions for lower respiratory illness. Data were obtained from the Swedish Hospital Discharge Register for all children with a first hospital admission before nine years of age, a total of 109, 176 children. The register covers more than $98 \%$ of all hospital admissions in Sweden. The coding of diagnoses was based on ICD-9 from 1987 to 1996 and ICD-I0 from 1997.

Results: The first admission rates declined significantly in children with a first admission after two years of age. However, an increasing admission trend was observed in children aged less than one year and $35 \%$ of first admissions occurred in this age group. The annual increase was $3.8 \%(95 \% \mathrm{Cl}$ I.3-6.3) in boys and $5.0 \%(95 \% \mathrm{Cl} 2.4-7.6)$ in girls. A diagnostic shift appeared to occur when ICD10 was introduced in 1997. The asthma and pneumonia admission rate in children aged less than one year levelled off, whereas the increase in admissions for bronchitis continued. The readmission rates for asthma decreased and the probability of re-admission was higher in boys. National drug statistics demonstrated a substantial increase in the delivery of inhaled steroids to all age groups but most prescriptions occurred to children aged one year or more.

Conclusion: Hospital admissions for lower respiratory illness are still increasing in children aged $<1$ year. Our findings are in line with other recent studies suggesting a change in the responsiveness to viral infections in very young children, but changes in admission criteria cannot be excluded. An increased use of inhaled steroids may have contributed to decreasing re-admission rates. 


\section{Background}

An increase in childhood wheezing has been seen in western countries over the last forty to fifty years [1]. The declining trend for hospital admissions among older children over the last decade can probably be explained by an improvement in the management of asthma [2]. The data relating to hospital admissions among very young children are, however, conflicting. Hospital admissions for asthma [3,4], wheezing symptoms [5] and lower respiratory illness [6] have increased in young children in the Nordic countries, whereas a declining trend was demonstrated in Canada [7] and Scotland [2]. Hospital admissions are more likely in boys but gender does not appear to affect the risk for re-admission [8].

Wheezing symptoms in early childhood are usually induced by viral infections. Asthma and wheezing bronchitis or bronchiolitis are partly overlapping entities in this age group. In this study, we have analysed the time trends in Sweden for hospital admissions and re-admissions for childhood asthma, acute bronchitis or bronchiolitis and pneumonia by gender and age at first admission, in particular admissions before 12 months of age. Our primary aim was to assess whether the previous increase in hospital admissions for lower respiratory illness had continued in young Swedish children. We have included re-admissions in our analyses in order to evaluate the burden of lower respiratory illness in very young children. We have also assessed whether changes in the labelling of symptoms have affected the time trend. Finally, we have analysed whether other acute illnesses in childhood have a similar trend.

\section{Methods}

This retrospective, population based study included all children under nine years of age admitted to any hospital in Sweden with a diagnosis of asthma, bronchitis/bronchiolitis or pneumonia during the study period 19872000. Data were obtained from the Swedish Hospital Discharge Register, which contains information on age, gender, medical diagnosis, date of admission, date of discharge and the personal identification code, which is unique to each citizen in Sweden. The register covers more than $98 \%$ of all hospital admissions in Sweden [9]. The study period included a change from the ninth revision of the International Classification of Diseases (ICD-9) to the tenth revision (ICD-10) in 1997. A diagnosis of asthma comprised the following codes in 1987-1996 (ICD-9): 493A, 493B, 493X, while in 1997-2000 (ICD 10) they were J45 and J46. The corresponding codes for bronchitis and bronchiolitis were 466, 490, 491C and 491X in 1987-1996 and J20-J21, J40 and J42 in 1997-2000. In the case of pneumonia and bronchopneumonia, the codes were 480-486 and 487A in 1987-1996 and J10.0, J11.0 and J12 - J18 in 1997-2000. Lower respiratory ill- ness includes asthma, bronchitis/bronchiolitis and pneumonia. The study comprised 109,176 children with first admissions for asthma, bronchitis or pneumonia in the following age groups: 38,119 children less than 12 months of age, 27,467 children 12-23 months of age, 25,035 children $24-35$ months of age and 18,555 children aged between four and eight years of age. A personal identification code was missing for 1.5 per cent of all children under nine years of age and for 2.2 per cent of the children aged one year and under. The Swedish population register from Statistics Sweden (SCB) was used to estimate the population at risk. The number of children below nine years of age was 451,607 in 1987 and 447,003 in 2000. The number of children below 12 months of age decreased from 53,345 in 1987 to 43,950 in 2000.

The Swedish Hospital Discharge Register also provided information about all first hospital admissions before nine years of age (all diagnoses) and for first hospital admissions for gastroenteritis $(008 \mathrm{H}-008 \mathrm{~W}, 009$ before 1997 and A08, A09 after 1996) and pseudocroup (464E before 1997 and J05.0 after 1996).

All the statistical analyses were conducted using the SAS version 8.2 statistical package (SAS Institute $A B$ ).

When studying age-specific trends, the number of children hospitalized for lower respiratory illness was related to the total number of children in Sweden in the corresponding age group. The rates were calculated as the number of first admissions per 1,000 children. When analysing trends for re-admissions, the rates were defined as the number of re-admissions per birth year. We have only included children with a first admission before 12 months of age and a re-admission within one year from the date of discharge.

Linear regression estimates of slopes with a 95\% CI (confidence interval, estimated using a multiplicative model assumption) were used to describe the historical time trend for first-time admissions for lower respiratory illness. To test for trends for re admissions, linear regression analysis was performed with re-admission rate as dependent variable and year of birth as the independent variable.

To describe the risk of re-admission as a function of time from the first admission, a survival function was performed using the Kaplan-Meier method.

To test for associations in fluctuations between admission rates, re-admission rates and age in days at first admission, a linear regression line was fitted to each of the variables with year of birth as the independent variable. The purpose of fitting a linear regression line was to obtain an estimation of the yearly deviations (residuals) from the 

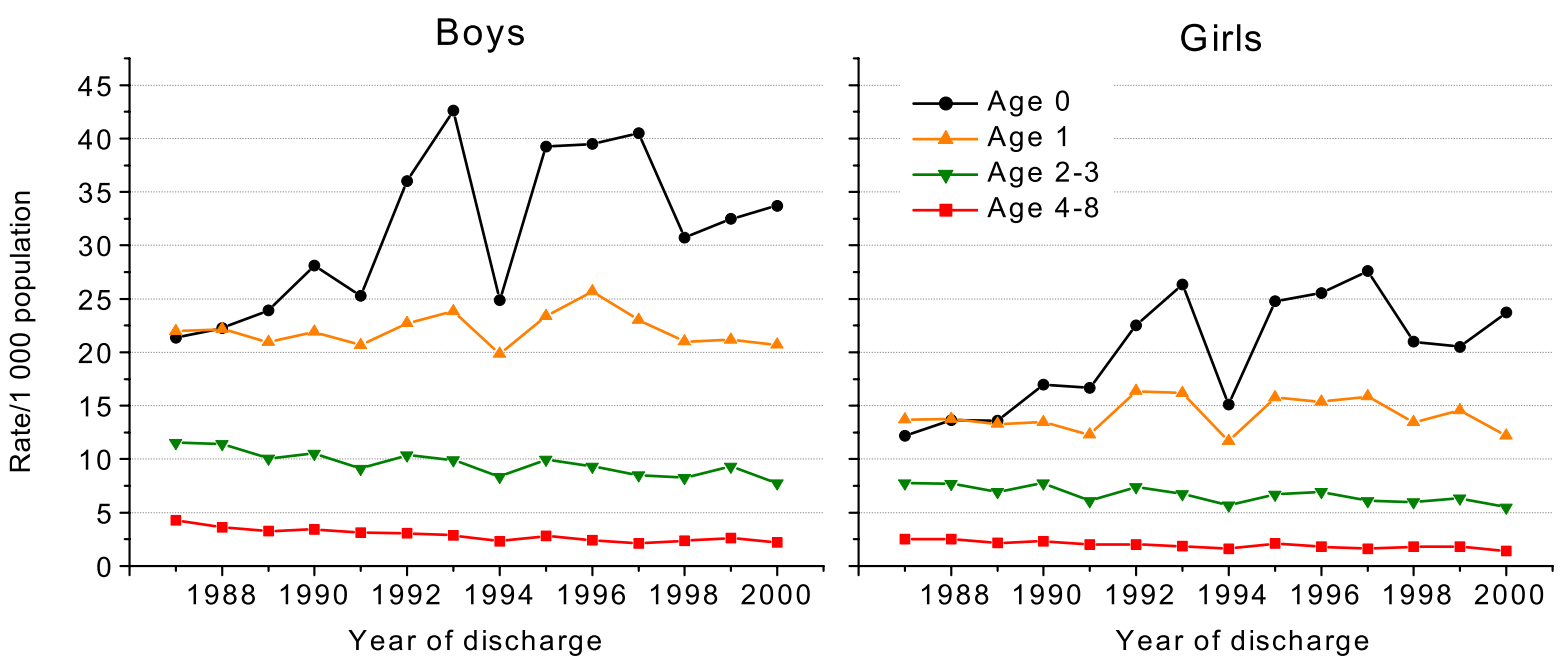

Figure I

Trend in lower respiratory illness 1987-2000.

overall trend. Pearson correlation coefficients with a 95\% CI between each pair of admission rates, re-admission rates and number of days to first admission were estimated using the residuals. Residuals were also re-calculated as the relative deviation from the fitted line instead of the absolute, in order to obtain an estimation independent of the level of the trend.

\section{Results}

Time trend first hospital admissions (all age groups)

Despite the substantial fluctuations over time for children hospitalised for lower respiratory illness, differences in time trends between the four age groups were apparent. First admissions for lower respiratory illness increased for boys and girls in the youngest age group (Fig. 1). On average, the yearly increase was 3.8\% (95\% CI 1.3-6.3) for boys and 5.0\% (95\% CI 2.4-7.6) for girls. No change was observed in the second age group (12 months-23 months). The admission rates decreased in children aged two years or more. There were no statistically significant differences in trend between boys and girls in any age group ( $>0.05$ for interaction term). However, admissions for lower respiratory illness were more common among boys than girls, particularly in the youngest age group where the admission rates were 59\% (95\% CI $44-$ 73 ) higher on average for boys than girls.

\section{Hospital admissions before one year of age}

There were substantial differences between first admission rates for asthma and pneumonia compared with bronchitis after 1996 (Fig. 2). From 1996 to 1997, asthma admission rates among boys decreased from 15/1,000 to 11/ 1,000 in children aged less than one year. Admissions for pneumonia displayed the same trend as asthma, with a decrease from $14 / 1,000$ to $8 / 1,000$. By contrast, first admissions for bronchitis increased from $14 / 1,000$ to almost 23/1,000. The corresponding rates for girls were $8 /$ 1,000 and 5/1,000 for asthma, $12 / 1,000$ to $7 / 1,000$ for pneumonia and $8 / 1,000$ and $17 / 1,000$ for bronchitis. These changes in admission rates coincided with the change from ICD9 to ICD10.

The increase in admissions for lower respiratory illness among children in the youngest age group cannot be explained by a general increase in hospital admissions. First hospital admissions for gastroenteritis and pseudocroup decreased in all age groups, even in children below 12 months of age. Admissions for croup declined from $16 / 1,000$ in 1987 to 5/1,000 in 2000 for boys and from $10 / 1,000$ to $2 / 1,000$ for girls. For gastroenteritis, the corresponding numbers were $15 / 1,000$ to $10 / 1,000$ for boys and 13/1,000 to 8/1,000 for girls. The total number of admissions (all diagnoses) declined between 1987 and 2000 from $250 / 1,000$ to $220 / 1,000$ for boys and from $200 / 1,000$ to $150 / 1,000$ for girls. 
First admissions because of asthma
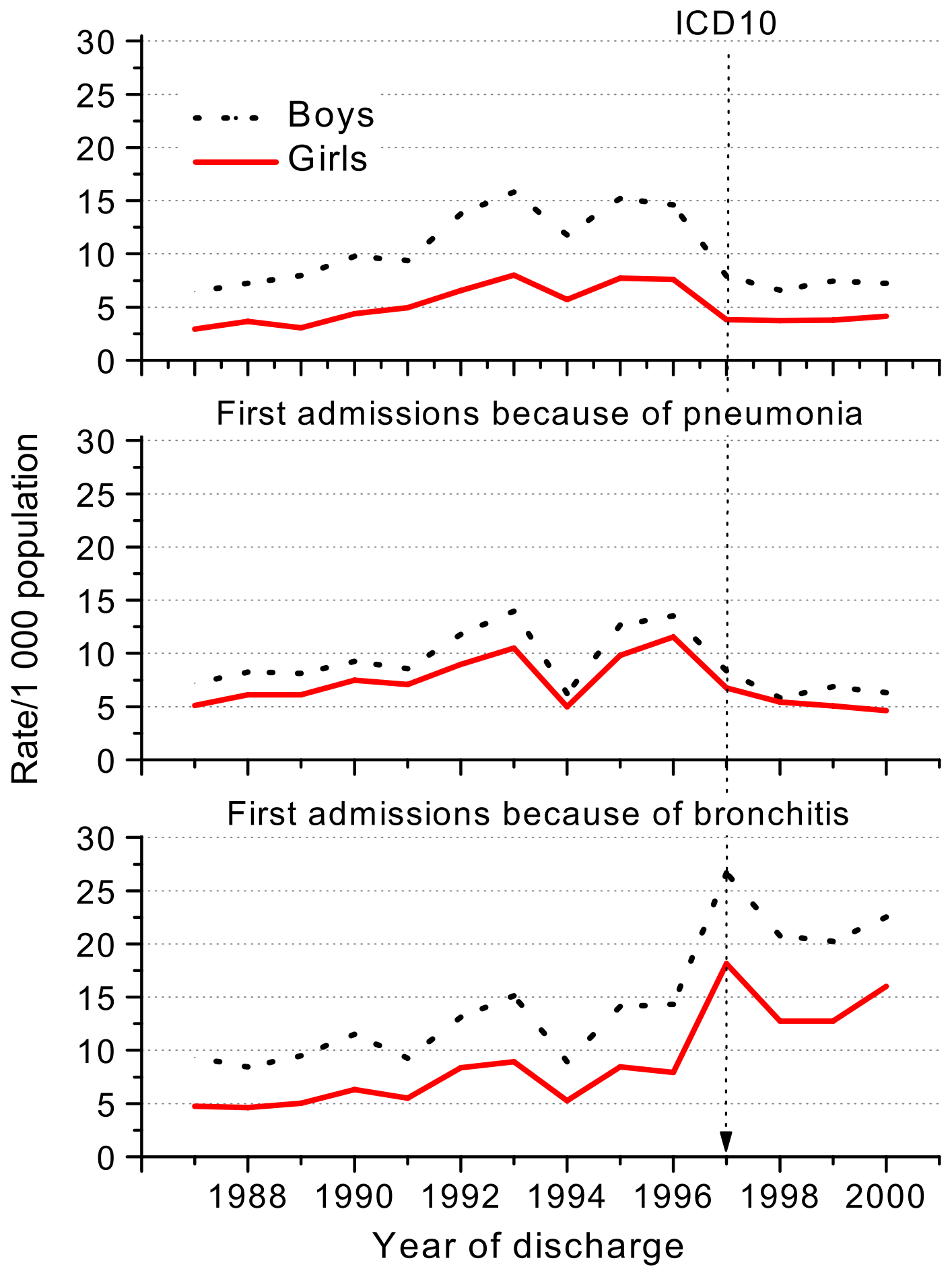

Figure 2

Time trend in first admissions for asthma, bronchitis/bronchiolitis and pneumonia before one year of age. 


\section{Re-admissions in children with a first admission before one year of age}

The risk of a child being re-admitted for lower respiratory illness decreased with time from the first admission. Almost 50 per cent of the re-admissions for wheezing illness had occurred within two months and 90\% within 9 months.

Fig. 3 shows the trend in re-admissions for asthma, bronchitis and pneumonia among boys and girls. The trend was significantly declining for asthma ( $p=0.001$ in boys and $\mathrm{p}=0.004$ in girls) and bronchitis ( $\mathrm{p}=0.04$ in boys). The decrease in asthma was most apparent between 1992 and 1993. The average re-admission rate for asthma in boys was 28\% between 1987 and 1992 and 20\% between 1993 and 1999. For girls, the corresponding numbers were $23 \%$ and $17 \%$. Re-admissions were more likely among boys ( $\mathrm{p}=0.007$ in asthma and $\mathrm{p}=0.001$ in bronchitis). The differences in re-admissions between boys and girls were reduced in recent birth cohorts.

A correlation was observed between annual fluctuations in first admissions, re-admissions and age at first admission (Fig. 4). Peaks in first admissions for lower respiratory illness coincide with reversed peaks in re-admissions and age at first admission. The correlations between admission rates/1,000 population and re-admission rates were -0.93 (95\% CI $-0.98,-0.78)$ for boys and $-0.89(95 \%$ CI $-0.97,-0.65)$ for girls. The correlations between admission rates/1,000 population and age in days at first admission were $-0.69(95 \% \mathrm{CI}-0.91,-0.20)$ for boys and -0.76 (95\% CI $-0.93,-0.33)$ for girls.

The consumption of inhaled steroids was fairly low in Sweden before 1986. A substantial increase in the delivery of inhaled steroids occurred in all age groups between 1987 and 1999 according to data from the Department of Drug Statistics, National Corporation of Swedish Pharmacies, Stockholm (Table 1).

\section{Discussion}

Our study covers all hospital admissions for wheezing illness in Sweden from 1987 through 2000, in all more than 80,000 first admissions. Differences in diagnostic routines between different hospitals and doctors are balanced by the very large data set in the Swedish Hospital Discharge Register. In conformity with other register studies [5$7,10]$, however, this study has certain limitations. The analyses are descriptive and restricted to the number of variables included in the registers. We have no information at an individual level on $e . g$. treatment or symptoms scores at admission. Therefore, we have to be cautious in the interpretation of our findings.
Hospitalisation for lower respiratory illness is a significant health care problem. First admissions for lower respiratory illness before one year of age have almost doubled over a period of thirteen years. A previous Swedish study indicated that the rise in hospitalisation started much earlier. A twofold increase in the hospitalisation rate for lower respiratory disease in children aged less than 12 months occurred in Stockholm between 1973 and 1991 [6].

Wheezing episodes during infancy are usually triggered by respiratory syncytial virus (RSV) infections. The fluctuations in hospitalisation rates from year to year are probably explained by recurrent RSV epidemics. We found that children tended to be younger at first admission and had fewer re-admissions in peak years. Re-admissions were more likely in children who had been admitted for asthma. Our findings are consistent with other studies showing that RSV-associated hospitalisations are more common in children younger than 6 months [11]. Only a subgroup of children with RSV-bronchiolitis will develop asthma [12]. Our survey also indicates that a diagnostic shift occurred in Sweden when the 10th revision of the International Classification of Diseases was introduced in 1997. The increase in first hospitalisation for lower respiratory illness after 1996 could be almost exclusively attributed to bronchitis/bronchiolitis, whereas hospitalisation rates for asthma and pneumonia had started to decline.

An upward trend for hospitalisation in very young children has also been reported from other countries in Europe and North America. A tenfold rise in hospitalisation for asthma was demonstrated in children aged less than two years between 1988 and 1997 in Kuopio, Finland. Observations from the USA and the Netherlands suggest that the increase in hospitalisation for wheezing illness has been caused by RSV bronchiolitis rather than asthma. Nationally representative data from the USA revealed that hospital admissions for bronchiolitis doubled between 1980 and 1996, whereas admissions for other lower respiratory tract diseases remained fairly stable [11]. A substantial increase in hospitalisation for bronchiolitis but no change in asthma hospitalisations was seen in the Netherlands in children aged 0-4 years from 1991 to 1999 [13]. A downward trend for hospitalisation for asthma in children below four years of age has been reported from Canada [7] and Scotland [2], but the authors did not discuss the trend for bronchitis and bronchiolitis in these papers. Our observations from Sweden suggest, firstly, that all forms of lower respiratory illness have to be included in trend assessments, since changes in diagnostic criteria will affect the trend for asthma. Secondly, the youngest children (particularly those less than one year of age) have to be analysed separately. 

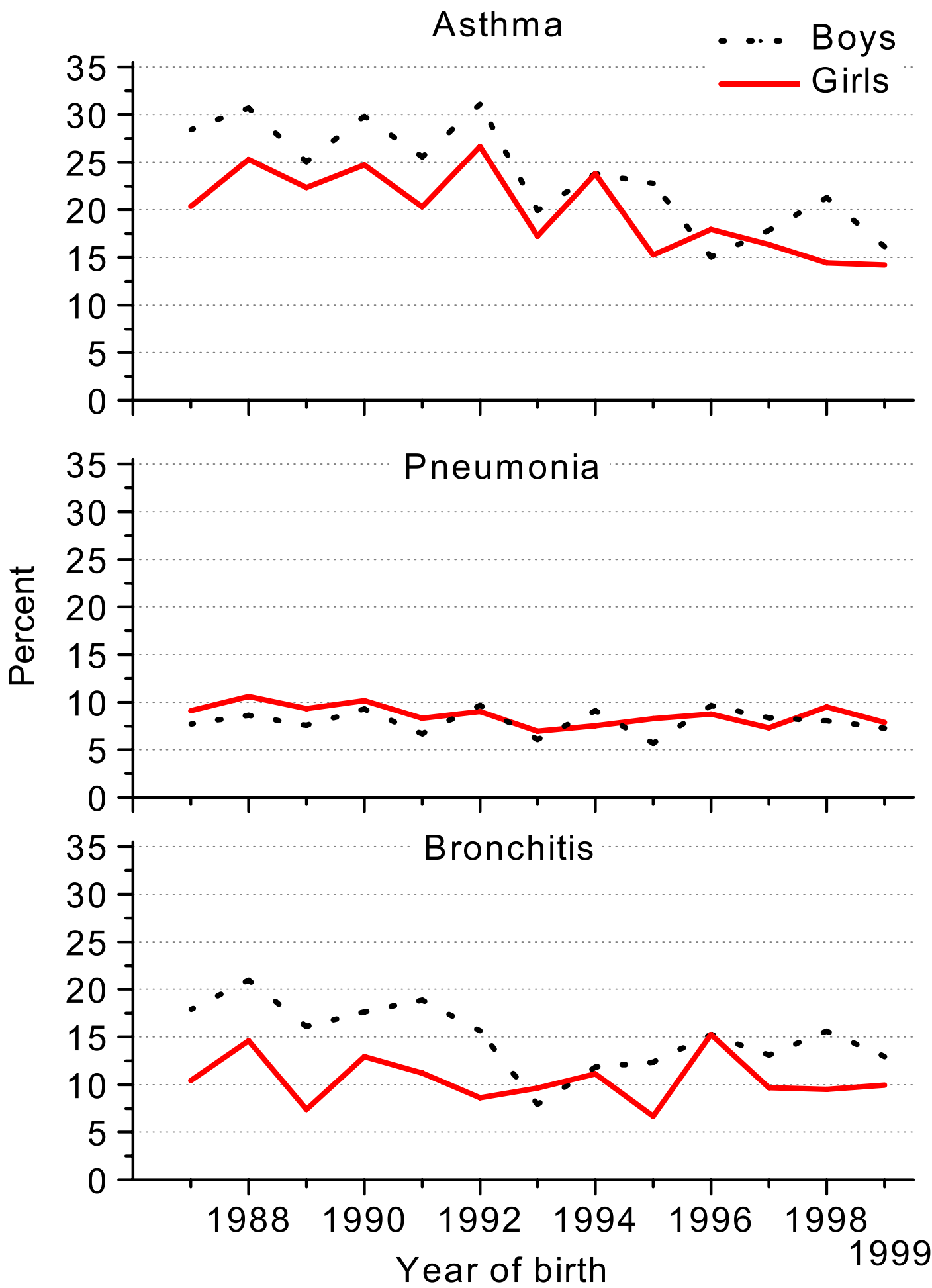

Figure 3

Time trend in re-admissions inside one year from first admission. First admission before 12 months. 


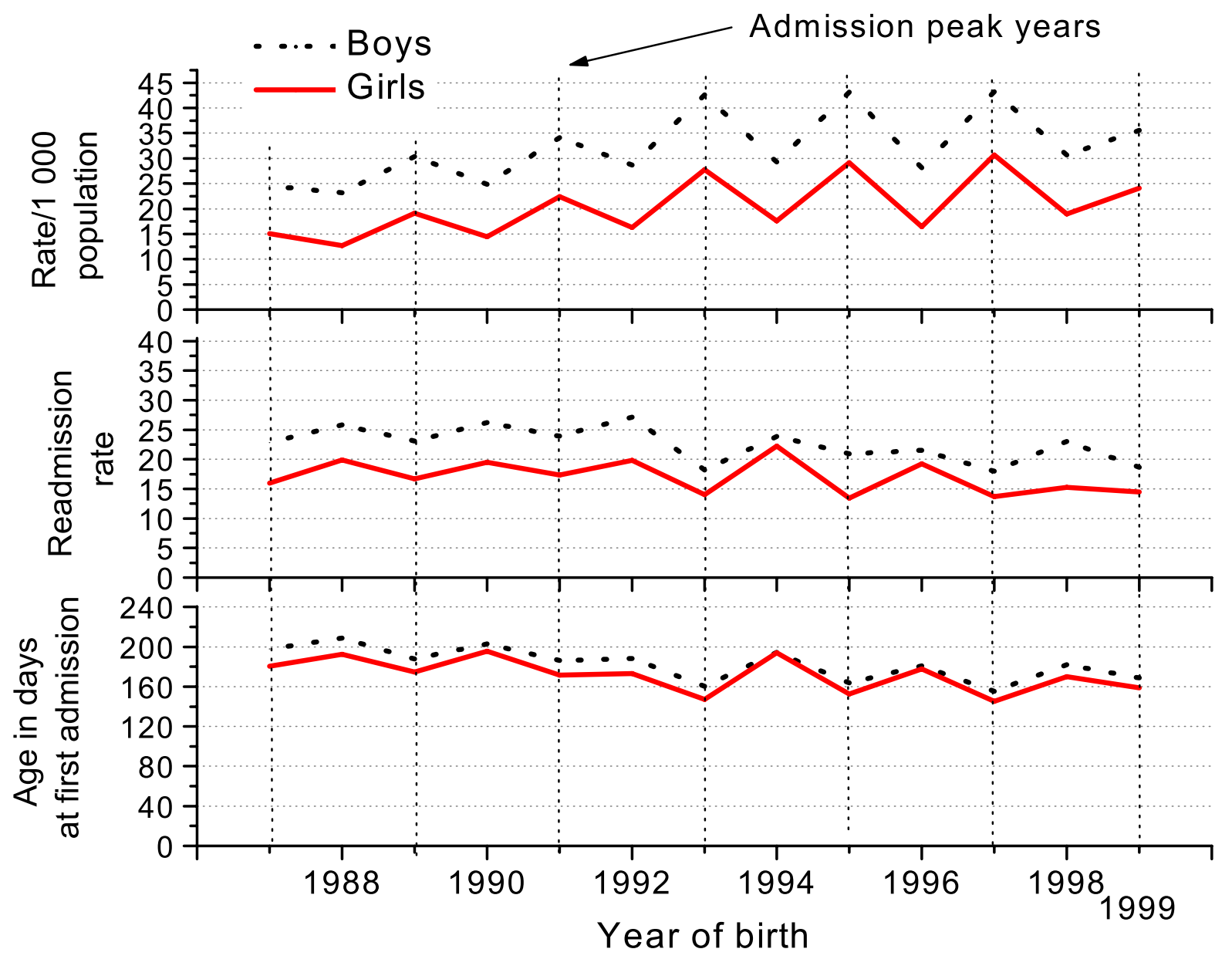

Figure 4

Fluctuations in admission peaks, re-admission rates and age at first admission for lower respiratory illness.

Table I: Delivery of inhaled steroids in Sweden to different age groups. The delivery of inhaled steroids was expressed as defined daily doses (DDD)/ 1000 inhabitants

\begin{tabular}{|c|c|c|c|c|c|c|c|c|c|c|c|c|c|c|}
\hline \multicolumn{15}{|l|}{ Year } \\
\hline Age & 86 & 87 & 88 & 89 & 90 & 91 & 92 & 93 & 94 & 95 & 96 & 97 & 98 & 99 \\
\hline 0 & 0.9 & 1.2 & 1.5 & 1.8 & 2.1 & 2.0 & 3.1 & 3.9 & 4.0 & 4.3 & 6.4 & 5.1 & 4.7 & 4.3 \\
\hline I & 4.3 & 5.2 & 6.0 & 5.5 & 7.2 & 7.6 & 10.7 & 11.7 & 13.6 & 19.4 & 33.5 & 19.3 & 20.3 & 20.6 \\
\hline $2-3$ & 4.3 & 7.1 & 8.4 & 8.0 & 10.2 & 10.7 & 12.2 & 14.7 & 18.4 & 24.1 & 40.4 & 21.8 & 22.4 & 22.6 \\
\hline 4-8 & 7.4 & 12.1 & 14.4 & 15.4 & 17.1 & 18.6 & 18.1 & 19.4 & 19.2 & 19.9 & 31.7 & 15.3 & 16.1 & 17.7 \\
\hline Total & 16.8 & 25.5 & 30.3 & 30.7 & 36.6 & 38.8 & 44.2 & 49.8 & 55.1 & 67.8 & 112.0 & 61.5 & 63.6 & 65.2 \\
\hline
\end{tabular}


A recent population-based study from the UK suggested an increase in all forms of wheezing disorder in very young children. The increase included non-atopic and virally-induced symptoms. There is no evidence of an increase in viral infections in very young children. An increase or change in responsiveness to viral infections is far more likely [14]. The causes of the increase in reactivity in very young children are so far uncertain. We have recently analysed the determinants of early hospitalisation for wheezing illness among children in Sweden [15]. Hospitalisation for wheezing illness was associated with young maternal age, low gestational age, low birth weight, number of older siblings and maternal smoking. Exposure to maternal smoking during pregnancy has been halved over the last fifteen years in Sweden and other factors are fairly stable. The risk of hospitalisation for wheezing illness is high in very premature children, but the number of children is small and does not affect the total hospitalisation rates. Bottle-feeding [16] and day-care attendance [17] are other important determinants of virally-induced wheezing during early childhood. However, breast-feeding rates are high in Sweden and very few children in Sweden start day care before one year of age.

More aggressive strains of RS virus could help to explain a rising admission trend, but an increase in the severity of lower respiratory symptoms has not been reported and readmissions are declining. Changes in admission criteria are also less plausible. It has been suggested that the increased use of pulse oximetry monitoring has contributed to more hospital admissions among children with bronchiolitis in the USA [11]. However, the increase in admissions in Sweden started long before the introduction of pulse oximetry. A shift has occurred in Swedish paediatric hospital care from in-patient to out-patient settings. Hospital admissions are declining for acute illnesses such as gastroenteritis and pseudocroup. The rise in admissions for lower respiratory illness coincided with the fall in admissions for croup. Falling admissions for croup were observed in all age groups. It is likely that successful out-patient care of children with croup has reduced the need for admission $[18,19]$.

The declining hospitalisation rate for asthma in children aged $>2$ years has been related to an increased prescription of inhaled steroids after $1985[5,10]$. In contrast, first hospital admissions for lower respiratory illness were still rising in children under one year of age despite an increased use of anti-inflammatory treatment also in this age group. Most prescriptions of inhaled steroids occurred to children aged one year or more. The effect of inhaled steroids on viral-induced wheezing in toddlers has been controversial [20]. Inhalation treatment is also more complicated in young children and poor compliance may contribute to a poor therapeutic response [21]. However, maintenance treatment with inhaled steroids could prevent symptoms in very young children [22]. A recent study from the Netherlands suggested that prescription of inhaled steroids at discharge reduced the risk for re-admission [23]. Therefore, it is possible that an increased use of inhaled steroids has contributed to the fall in re-admissions for asthma in children with first admission during infancy.

In agreement with other studies, we found that a major part of all re-admissions occurred within a few months after discharge $[8,23]$. Re-admissions for asthma and bronchitis were more likely in boys. This finding is difficult to explain. Previous studies in other countries do not indicate that male gender should be a risk factor for readmission $[2,4,8,23]$. However, the time trend suggested that the differences in re-admission rates between boys and girls tend to disappear also in Sweden.

\section{Conclusions}

This study illustrates the burden of lower respiratory illness in very young children. First hospital admissions for lower respiratory illness before one year of age have been doubled in Sweden between 1987 and 2000. Diagnostic criteria for asthma and bronchitis are less distinct in young children. Changes in the labelling of wheezing symptoms may complicate comparisons in trends. A diagnostic shift appeared to occur in Sweden, when ICD-10 was introduced in 1997. Hospital admissions for asthma and pneumonia stabilised whereas the rise of admissions for bronchitis continued. Increasing hospitalisation rates for lower respiratory illness could be related to an increase in susceptibility and a change in responsiveness to viral infections in very young children. A reduced admission threshold is less likely since re-admissions are declining and hospital admissions for other acute illnesses are falling. The reasons for an increased reactivity to viral infections are so far uncertain. The rise of lower respiratory illness in Sweden has occurred despite a substantial decline in maternal smoking, a high breast feeding rate and very few children in day care before one year of age.

\section{Competing interests}

None declared.

\section{Authors' contributions}

The study was conceived by LB and designed by LB and $\mathrm{OB}$ in collaboration.

OB performed the statistical analysis. The paper was drafted, approved and corrected by OB and LB.

\section{Acknowledgements}

The authors wish to thank Fereshte Ebrahim and Leif Forsberg at the National Board of Health and Social Welfare, Sweden, for providing us with the data set. 


\section{References}

I. von Mutius E: The environmental predictors of allergic disease J Allergy Clin Immunol 2000, 105:9-19.

2. Morrison DS and McLoone $P$ : Changing patterns of hospital admission for asthma, I 98I-97 Thorax 200I, 56:687-690.

3. Malmstrom K, Korhonen K, Kaila M, Dunder T, Nermes M, Klaukka $\mathrm{T}$, Sarna $S$ and Juntunen-Backman K: Acute childhood asthma in Finland: a retrospective review of hospital admissions from I 976 to I 995 Pediatr Allergy Immunol 2000, I I:236-240.

4. Jonasson G, Lodrup Carlsen KC, Leegaard J, Carlsen KH, Mowinckel $\mathrm{P}$ and Halvorsen KS: Trends in hospital admissions for childhood asthma in Oslo, Norway, I 980-95 Allergy 2000, 55:232239.

5. Wennergren G and Strannegard IL: Asthma hospitalizations continue to decrease in schoolchildren but hospitalization rates for wheezing illnesses remain high in young children Acta Paediatr 2002, 91: I239-1245.

6. Wickman M, Farahmand BY, Persson PG and Pershagen G: Hospitalization for lower respiratory disease during 20 yrs among under 5 yr old children in Stockholm County: a population based survey European Respiratory Journal 1998, I I:366-370.

7. Crighton EJ, Mamdani MM and Upshur RE: A population based time series analysis of asthma hospitalisations in Ontario, Canada: 1988 to 2000 BMC Health Serv Res 2001, I:7.

8. To T, Dick P, Feldman W and Hernandez R: A cohort study on childhood asthma admissions and readmissions Pediatrics 1996, 98:191-195.

9. The National Board of Health and Welfare.: The Swedish Hospital Discharge Register 2001 [http://www.sos.se/epc/].

10. Wennergren G, Kristjansson S and Strannegard IL: Decrease in hospitalization for treatment of childhood asthma with increased use of antiinflammatory treatment, despite an increase in prevalence of asthma J Allergy Clin Immunol 1996, 97:742-748.

II. Shay DK, Holman RC, Newman RD, Liu LL, Stout JW and Anderson LJ: Bronchiolitis-associated hospitalizations among US children, I980-1996 Jama 1999, 282: |440-| 446.

12. Weinberger M: Clinical patterns and natural history of asthma J Pediatr 2003, I42:SI5-9; discussion SI 9-20.

13. van Woensel JB, van Aalderen WM, Kneyber MC, Heijnen ML and Kimpen JL: Bronchiolitis hospitalisations in the Netherlands from I99I to I999 Arch Dis Child 2002, 86:370-37I.

14. Kuehni CE, Davis A, Brooke AM and Silverman M: Are all wheezing disorders in very young (preschool) children increasing in prevalence? Lancet 2001, 357:1821-1825.

15. Braback L, Bjor $O$ and Nordahl G: Early determinants of first hospital admissions for asthma and acute bronchitis among Swedish children Acta Paediatr 2003, 92:27-33.

16. Sherriff A, Peters T], Henderson J and Strachan D: Risk factor associations with wheezing patterns in children followed longitudinally from birth to 3(1/2) years Int J Epidemiol 200I, 30:14731484.

17. Nafstad P, Hagen JA, Oie L, Magnus P and Jaakkola JJ: Day care centers and respiratory health Pediatrics 1999, 103:753-758.

18. Klassen TP: Effectiveness of glucocorticoids in treating croup. Authors acknowledge Cochrane Collaboration Bmj 1999, 3 19:1577.

19. Brown JC: The management of croup Br Med Bull 2002, 6 I:189202.

20. Meissner HC: Uncertainty in the management of viral lower respiratory tract disease Pediatrics 2001, 108:1000-1003.

21. Marguet C, Couderc L, Le Roux P, Jeannot E, Lefay $V$ and Mallet E: Inhalation treatment: errors in application and difficulties in acceptance of the devices are frequent in wheezy infants and young children Pediatr Allergy Immunol 200 I, I 2:224-230.

22. Wennergren G, Nordvall SL, Hedlin G, Moller C, Wille S and Asbrink Nilsson E: Nebulized budesonide for the treatment of moderate to severe asthma in infants and toddlers Acta Paediatr 1996, 85: $183-189$.

23. Wever-Hess J, Hermans J, Kouwenberg JM, Duiverman EJ and Wever AM: Hospital admissions and readmissions for asthma in the age group 0-4 years Pediatr Pulmonol 200 I, 3 I:30-36.

\section{Pre-publication history}

The pre-publication history for this paper can be accessed here:

http://www.biomedcentral.com/1471-2458/3/22/prepub
Publish with Bio Med Central and every scientist can read your work free of charge

"BioMed Central will be the most significant development for disseminating the results of biomedical research in our lifetime. "

Sir Paul Nurse, Cancer Research UK

Your research papers will be:

- available free of charge to the entire biomedical community

- peer reviewed and published immediately upon acceptance

- cited in PubMed and archived on PubMed Central

- yours - you keep the copyright

Submit your manuscript here:

http://www.biomedcentral.com/info/publishing_adv.asp
BiolMedcentral 